\title{
Corticotropin-Releasing Factor within the Central Nucleus of the Amygdala Mediates Enhanced Ethanol Self- Administration in Withdrawn, Ethanol-Dependent Rats
}

\author{
Cindy K. Funk, ${ }^{1}$ Laura E. 0’Dell, ${ }^{2}$ Elena F. Crawford, ${ }^{1}$ and George F. Koob ${ }^{1}$ \\ ${ }^{1}$ The Scripps Research Institute, La Jolla, California 92037, and ${ }^{2}$ The University of Texas El Paso, El Paso, Texas 79968
}

\begin{abstract}
Alcohol dependence is characterized by excessive consumption, loss of control over intake, and the presence of a withdrawal syndrome, including both motivational and physical symptoms. The motivational symptoms, including anxiety, have been hypothesized to be important factors eliciting excessive drinking during abstinence. Previous work has shown that ethanol-dependent rats also display enhanced anxiety-like behaviors and enhanced ethanol self-administration during withdrawal, likely resulting from dysregulation of brain corticotropin-releasing factor (CRF) stress systems. The present study was designed to explore the brain sites within the extended amygdala [central nucleus of the amygdala (CeA), lateral bed nucleus of the stria terminalis (BNST), and nucleus accumbens shell $(\mathrm{NAcSh})]$ that mediate the increased ethanol self-administration observed during withdrawal. Ethanol-dependent animals showed an increase in ethanol self-administration after acute withdrawal relative to nondependent controls. The CRF antagonist D-Phe-CRF $12-41$ ( $\left[\mathrm{D}-\mathrm{Phe}^{12}, \mathrm{Nle}^{21,38}, \mathrm{C} \alpha \mathrm{MeLeu}^{37}\right]-\mathrm{rCRF}_{(12-41)}$ ) was administered into the CeA, lateral BNST, or NAcSh of acute-withdrawn dependent and nondependent rats. Administered into the $\mathrm{CeA}$, the antagonist reduced ethanol self-administration in dependent animals, with no effect in nondependent animals. Administration of D-Phe- $\mathrm{CRF}_{12-41}$ into the lateral BNST and NAcSh was without effect on ethanol selfadministration in dependent and nondependent animals. At the same time point of withdrawal, there was a decrease in CRF immunoreactivity within the $\mathrm{CeA}$, suggesting an increased extracellular release of CRF during withdrawal. There was no change in CRF immunoreactivity in the BNST or NAcSh. These results indicate that CRF, specifically within the CeA, plays a role in mediating excessive ethanol consumption in ethanol-dependent animals.
\end{abstract}

Key words: ethanol; central amygdala; self-administration; rat; CRF; lateral BNST; nucleus accumbens shell

\section{Introduction}

Alcoholism is a chronic relapsing disorder characterized by compulsive use of alcohol and a loss of control over intake. As dependence develops, there is a shift from controlled use to uncontrolled, excessive consumption of alcohol, which has been argued to be a shift from positive to negative reinforcement ultimately driving continued alcohol use (Koob, 2003; Koob et al., 2004). Cessation of chronic alcohol use is often accompanied by negative emotional symptoms, such as increased anxiety, and alleviation of these negative emotional states is hypothesized to be a major driving force for continued alcohol consumption (Hershon, 1977; Koob, 2003). Similar to human alcoholics, ethanoldependent animals display enhanced anxiety-like behaviors and excessive ethanol self-administration during periods of withdrawal (Baldwin et al., 1991; Becker, 1999; Roberts et al., 2000;

Received July 20, 2006; revised Sept. 1, 2006; accepted Sept. 21, 2006.

This work was supported by the Pearson Center for Alcoholism and Addiction Research and National Institutes of Health Grants AA06420 (G.F.K.) and AA015239 (C.K.F.) from the National Institute on Alcohol Abuse and Alcoholism. This is publication number 18367 from The Scripps Research Institute. We thank Mike Arends for his editorial assistance and Krisha Begalla and Maury Cole for technical assistance. We thank Jean Rivier for his generous gift of D-Phe-CRF $12-41$.

Correspondence should be addressed to Dr. Cindy K. Funk, The Scripps Research Institute, 10550 North Torrey Pines Road, SP-30-2400, La Jolla, CA 92037. E-mail: creiter@scripps.edu.

D0I:10.1523/JNEUROSCI.3096-06.2006

Copyright $\odot 2006$ Society for Neuroscience ～0270-6474/06/2611324-09\$15.00/0
Overstreet et al., 2002; Rimondini et al., 2002; Becker and Lopez, 2004; O'Dell et al., 2004), providing a model system for studying the motivational changes associated with ethanol dependence.

Dysregulation of brain corticotropin-releasing factor stress systems has been implicated in mediating increased anxiety-like behaviors during withdrawal (Menzaghi et al., 1994). Regions of the extended amygdala [central nucleus of the amygdala (CeA), lateral bed nucleus of the stria terminalis (BNST), and nucleus accumbens shell (NAcSh)] comprise part of the "extrahypothalamic" CRF system. These nuclei contain high amounts CRF terminals, cell bodies, and receptors (Merchenthaler et al., 1982; Van Pett et al., 2000; Dong et al., 2001), and numerous studies have demonstrated an involvement of the extended amygdala in mediating the behavioral and physiological responses associated with anxiety (LeDoux et al., 1988; Walker and Davis, 1997). The increased anxiety-like behaviors during ethanol withdrawal are believed to result, in part, from increased extracellular CRF within the extended amygdala (Merlo Pich et al., 1995; Olive et al., 2002), and central administration of CRF antagonists can attenuate these behaviors (Baldwin et al., 1991; Rassnick et al., 1993; Valdez et al., 2002). Ethanol-dependent animals also orally self-administer increased amounts of ethanol during withdrawal (Roberts et al., 2000; Becker and Lopez, 2004; O'Dell et al., 2004), effects also blocked by decreasing CRF activity (Valdez et al., 2002). 
CRF antagonists, injected intracerebroventricularly, reduce both the enhanced anxiety-like behaviors and excessive ethanol consumption during withdrawal (Valdez et al., 2002). Unknown are the specific sites within the extended amygdala responsible for the CRF component of excessive drinking. The purpose of the present study was to explore the role of CRF, within the extended amygdala, in mediating excessive ethanol self-administration during acute withdrawal. Using an intermittent ethanol vapor exposure paradigm to induce dependence in Wistar rats (O'Dell et al., 2004), it is reported here that a CRF receptor antagonist, when administered intra-CeA, selectively reduces ethanol selfadministration in ethanol-dependent, but not nondependent, animals. The antagonist was without effect when administered intra-BNST or intra-NAcSh. Furthermore, CRF immunoreactivity within the CeA, but not the BNST or NAcSh, is decreased during acute withdrawal in dependent animals. These data indicate that CRF within the CeA plays an important role in mediating excessive ethanol consumption during withdrawal in ethanol-dependent animals.

\section{Materials and Methods}

Animals. Sixty-eight male Wistar rats weighing 180-200 g at the start of the experiment were obtained from Charles River Laboratories (Kingston, NY). Animals were housed two to three per cage with food and water available ad libitum. Lights were on a $12 \mathrm{~h}$ light/dark cycle, with lights on at 6:00 A.M. All procedures met the guidelines of the National Institutes of Health Guide for the Care and Use of Laboratory Animals.

Drugs. Ethanol (10\% w/v), for oral self-administration, was prepared using 95\% ethyl alcohol and water. The nonspecific peptide CRF antagonist D-Phe-CRF ${ }_{12-41}\left(\left[\mathrm{D}-\mathrm{Phe}^{12}, \mathrm{Nle}^{21,38}, \mathrm{C} \alpha \mathrm{MeLeu}^{37}\right]-\mathrm{rCRF}_{(12-41)}\right)$ was provided by Dr. Jean Rivier (The Salk Institute for Biological Studies, La Jolla, CA). Immediately before use, D-Phe-CRF ${ }_{12-41}$ was dissolved in $0.5 \times$ PBS, $\mathrm{pH} 7.4$, and kept on ice until injection. All injections were given intracranially, 5 min before operant self-administration testing.

Operant ethanol self-administration. Ethanol self-administration was established in standard operant chambers (Coulbourn Instruments, Allentown, PA) housed in sound-attenuated ventilated cubicles. Animals were trained to orally self-administer ethanol or water in a concurrent, two-lever, free-choice contingency. Syringe pumps (Razel Scientific Instruments, Stamford, CT) dispensed ethanol or water into two stainless steel drinking cups mounted $4.0 \mathrm{~cm}$ above the grid floor in the middle of one side panel. Two retractable levers were located $4.5 \mathrm{~cm}$ to either side of the drinking cups. Fluid delivery and recording of operant selfadministration were controlled by a microcomputer. Lever presses were not recorded during the $0.5 \mathrm{~s}$ in which the pumps were active. A continuous reinforcement [fixed ratio-1 (FR1)] schedule was used such that each response resulted in delivery of $0.1 \mathrm{ml}$ of fluid. Fluid delivery and recording of operant responding were controlled by a microcomputer.

Rats were trained to press a lever for ethanol using a modification of the sweetened solution fading procedure (Samson, 1986). No fluid or food restriction period was used. This training method culminates in rats consuming sufficient unsweetened $10 \%$ ethanol to produce pharmacologically relevant blood alcohol levels (BALs) (Roberts et al., 1999). Rats were initially trained to press a lever for a sweetened solution containing glucose $(3 \% \mathrm{w} / \mathrm{v})$ and saccharin $(0.125 \% \mathrm{w} / \mathrm{v})$ (Sigma, St. Louis, MO). Ethanol self-administration was initiated by adding ethanol ( $10 \% \mathrm{w} / \mathrm{v})$ to the sweetened solution for $4-5 \mathrm{~d}$, followed by $4-5 \mathrm{~d}$ of $10 \%$ ethanol plus $0.125 \%$ saccharin only. Finally, the animals received the $10 \%$ ethanol solution alone. During all training sessions, rats were also allowed to press for water on the opposite lever. The lever that produced water or ethanol was altered daily to prevent selecting rats biased toward one lever. The animals received daily ( $5 \mathrm{~d}$ per week) $30 \mathrm{~min}$ access to ethanol for $20-25 \mathrm{~d}$ until stable rates of intake were observed. The criterion for stable baseline intake was $\pm 20 \%$ across three consecutive sessions. Testing was performed at 8:00 A.M. (lights on at 6:00 A.M.).

Ethanol vapor exposure procedure. To induce ethanol dependence, two standard rat cages were housed in separate, sealed, clear plastic chambers into which ethanol vapor was intermittently introduced. Ethanol vapor was created by dripping 95\% ethanol into $2000 \mathrm{ml}$ Erlenmeyer vacuum flasks kept at $50^{\circ} \mathrm{C}$ on a warming tray. Air was blown over the bottom of the flask at $11 \mathrm{~L} / \mathrm{min}$ to vaporize the ethanol. The concentration of ethanol vapor delivered was adjusted by varying the rate at which ethanol was pumped into the flasks and ranged from 22 to $27 \mathrm{mg} / \mathrm{L}$. The chambers were connected to a timer that would turn the ethanol vapor on (4:00 P.M.) and off (6:00 A.M.) every day, allowing animals to receive ethanol vapor for $14 \mathrm{~h}$ and control air for $10 \mathrm{~h}$ (O'Dell et al., 2004). Blood samples were taken at 6:00 A.M. for BAL determination every $3 \mathrm{~d}$ during vapor exposure. Tail blood $(0.5 \mathrm{ml})$ was collected into heparinized Eppendorf tubes. After centrifugation, the plasma was extracted with trichloroacetic acid and assayed for ethanol content using the nicotinamide adenine dinucleotide-alcohol dehydrogenase enzyme spectrophotometric method (Sigma). Target BALs were 150-200 mg\% across a 4 week exposure period. This paradigm has been shown to produce physical dependence, demonstrated by the appearance of somatic withdrawal signs after removal from the chambers (Roberts et al., 2000; O’Dell et al., 2004).

Intracerebral cannulations and drug infusions. Rats were anesthetized with an isoflurane-oxygen mixture, and 26 gauge, $7.5 \mathrm{~mm}$ stainless steel guide cannulas (Plastics One, Roanoke, VA) aimed $2 \mathrm{~mm}$ above the desired brain regions were stereotaxically implanted bilaterally. With the incisor bar set at -3.3 from interaural 0 (flat skull), the coordinates were as follows: CeA, $-2.6 \mathrm{~mm}$ anteroposterior, $\pm 4.2 \mathrm{~mm}$ mediolateral, -5.2 dorsoventral from dura; lateral BNST, $-0.35 \mathrm{~mm}$ anteroposterior, \pm 3.5 $\mathrm{mm}$ mediolateral ( $15^{\circ}$ vertical tilt), -4.5 dorsoventral from dura; and NAcSh, $+1.7 \mathrm{~mm}$ anteroposterior, $\pm 1.0 \mathrm{~mm}$ mediolateral, -5.6 dorsoventral from dura (Paxinos and Watson, 1998). The guide cannulas were secured to the skull with dental cement and anchor screws, and guide cannulas were inserted with stylet wires to protect the brain tissue. Rats were allowed to recover at least $5 \mathrm{~d}$ before continuation of experiments.

Intracerebral injections were administered with the use of injectors ( 33 gauge; Plastics One) that projected $2 \mathrm{~mm}$ past the guide cannula into the desired brain region. The injectors were attached to $70 \mathrm{~cm}$ of calibrated polyethylene-20 tubing preloaded with drug solution. Injection volumes were $0.5 \mu \mathrm{l} /$ side, infused over $1 \mathrm{~min}$ using Hamilton microsyringes connected to the injectors with polyethylene tubing. Drug delivery was controlled by a Harvard Apparatus (Holliston, MA) infusion pump. After drug delivery, the injectors were left in place for $60 \mathrm{~s}$ and then replaced with the protective wire stylets. After a 5 min preincubation period, the animals were then placed into the self-administration chambers for testing.

Histology. At the completion of the experiment, animals were killed with an overdose of pentobarbital and perfused transcardially, first with saline and then with a $4 \%$ paraformaldehyde solution. Brains were subsequently removed from the skull and frozen. The brains were sectioned in $60 \mu \mathrm{m}$ slices, mounted, and stained with cresyl violet. Injection sites were verified under a light microscope. Only animals with correct, bilateral cannula placements were used for statistical analysis. In the CeA study, four animals had incorrect probe placements and were removed from the group. Three animals were removed from the NAcSh group, and five animals were removed from the lateral BNST group because of incorrect probe placement.

CRF immunohistochemistry. Rats were heavily anesthetized with pentobarbital, pre-perfused transcardially with a solution of $0.5 \mathrm{ml}$ heparin/ $100 \mathrm{ml}$ saline for 1-2 min, and then perfused with a solution of $4 \%$ paraformaldehyde in $0.1 \mathrm{M}$ PBS, $\mathrm{pH} 7.3$, for $11 \mathrm{~min}$ with a flow rate of 22 $\mathrm{ml} / \mathrm{min}$. Brains were removed, postfixed for $24 \mathrm{~h}$ in paraformaldehyde, transferred to PBS containing 16\% sucrose, and sequentially transferred to 18 and $20 \%$ sucrose solutions. Brains were frozen on dry ice, and serial coronal CeA, BNST, and NAcSh sections of $40 \mu \mathrm{m}$ were obtained using an American Optical (Buffalo, NY) sliding microtome. All sections were collected free-floating in either PBS for immediate use or in a cryoprotectant storing solution for future analysis.

Control and experimental groups were run in parallel within the same immunohistochemical procedures. Free-floating sections were rinsed in PBS, incubated for $20 \mathrm{~min}$ in $1 \%$ hydrogen peroxide PBS solution to quench endogenous peroxidase activity, rinsed several times in PBS, and incubated in a blocking solution containing $0.1 \%$ bovine serum albumin 
(BSA), 10\% normal horse serum, and $0.3 \%$ Triton X-100 in PBS for 30-60 min. Sections were incubated in either PBS as a control or goat anti-CRF polyclonal antibody diluted 1:500 to 1:1000 (Santa Cruz Biotechnology, Santa Cruz, CA) in PBS containing 0.3\% Triton X-100, 0.1\% $\mathrm{BSA}$, and $2 \%$ normal horse serum for $24 \mathrm{~h}$ at $4^{\circ} \mathrm{C}$.

After incubations in the primary antibody, sections were rinsed three times for $10 \mathrm{~min}$ in PBS and processed with an avidin/biotin horseradish peroxidase complex ABC kit (Vector Laboratories, Burlingame CA.). Briefly, all samples were incubated in a secondary biotinylated anti-goat antibody, rinsed in PBS, and incubated in an avidin/biotin horseradish peroxidase solution. Immunoreactivity was visualized using a DAB substrate kit (Vector Laboratories). After several rinses in PBS, sections were mounted on coated glass slides, air dried, dehydrated through a series of graded ethanols and xylene, and permanently coverslipped. Sections were analyzed under bright field using a Zeiss (Oberkochen, Germany) Axiophot microscope equipped with a Zeiss AxioCamMRc digital camera for photography.

Experimental procedure. Rats were first trained to self-administer 10\% ethanol on an FR1 schedule of reinforcement. Once stable baseline responding was attained, rats were surgically implanted with bilateral intracerebral cannulas aimed at the CeA, lateral BNST, or NAcSh. After recovery from surgery, self-administration sessions were resumed for $\sim 2$ weeks to reestablish baseline ethanol self-administration, and subsequently the animals were transferred to ethanol (dependent group) or control (nondependent group) vapor chambers for a 4 week exposure period. At the end of the 4 week period of dependence induction, rats were retested for ethanol self-administration or killed for immunohistochemistry after a $2 \mathrm{~h}$ withdrawal period from ethanol vapors. At this time point, dependent animals display a significant increase in ethanol lever pressing (Valdez et al., 2002). A Latin square design was used to test the effects of intracerebral administration of D-Phe-CRF ${ }_{12-41}(0.0,0.125$, 0.25 , and $0.5 \mu \mathrm{g} / \mu \mathrm{l})$. Separate groups of rats were used for each brain region. Test sessions were separated by $6 \mathrm{~d}$, during which time the animals were returned to the ethanol or control vapor chambers.

CRF density measurements. The relative density of CRFimmunoreactive cell bodies, fibers, and terminals in the CeA and the BNST were graded. Five $40 \mu \mathrm{m}$ serial sections through the CeA and the BNST for each animal were used for analysis. Bright-field digital images were acquired using a Zeiss Axiphot microscope equipped with a Zeiss AxioCamMRc digital camera. All photographs were taken at $20 \times$ magnification using identical light intensity and exposure times. All images were imported into Scion (Frederick, MD) Image version 1.63 based on NIH Image, and the black and white images were inverted to simulate dark-field illumination. Three separate standard area contours were drawn for each digital image. The selected contours included one for positive CRF immunoreactivity, one for negative control areas (no immunoreactivity), and one for nonspecific DAB background with no specific CRF immunoreactivity. Mean optical density numbers were derived by subtracting the negative background and the nonspecific DAB background from the positive CRF-immunoreactive areas.

Quantification of CRF-positive cell bodies. Quantitative analysis to obtain unbiased estimates of the total number of CeA CRF-positive cell bodies was performed on a Zeiss Axiophot Microscope equipped with MicroBrightField (Colchester, VT) Stereo Investigator software, a threeaxis Mac 5000 motorized stage (Ludl Electronics Products, Hawthorne, NY), a digital CCCD ZVS video camera (Zeiss, Thornwood, NY), PCI color frame grabber, and personal computer workstation. All $40 \mu \mathrm{m}$ sections from the CeA were saved in strict anatomical order. Systematic random sampling of the CeA consisted of a one-in-six section analysis, and five sections were analyzed per animal. Live video images were used to draw contours delineating the CeA. All contours were drawn at low magnification using a Zeiss Neoflaur $5 \times$ objective, numerical aperture 0.15 . After determination of mounted section thickness, $Z$-plane values, and selection of contours, an optical fractionator analysis was used to determine CRF-positive neuron number. A counting frame of appropriate dimensions denoting forbidden and nonforbidden was superimposed on the video monitor, and the optical fractionator analysis was performed using a Zeiss Plan Apochromat $63 \times$ oil objective, numerical aperture 1.4 and a 1.4 auxillary condenser lens. Cells were identified as neurons based on standard morphology, and only neurons with a focused nucleus within the nonforbidden regions of the counting frame were counted.

Statistical analyses. Data were analyzed using a mixed two-way ANOVA with vapor treatment (ethanol or control) as the betweensubjects factor and antagonist dose (D-Phe- $\mathrm{CRF}_{12-41}$ ) as a withinsubjects factor. Tukey's (A) honestly significant test was used for post hoc analysis of individual means $(p<0.05)$. Immunohistochemistry data were analyzed using Student's t test.

\section{Results}

Effects of the CRF receptor antagonist D-Phe-CRF $\mathrm{C}_{12-41}$ administered intra-CeA on ethanol and water selfadministration in dependent and nondependent rats

For the CeA group (dependent, $n=10$; nondependent, $n=9$ ), animal weights at the end of the experiment were $536.6 \pm 25.9 \mathrm{~g}$ for nondependent rats and $533.3 \pm 21.3 \mathrm{~g}$ for dependent rats. Levels of ethanol lever responding, before exposure to chronic vapors, were $20.7 \pm 1.6$ presses (dependent) and $19.3 \pm 1.9$ presses (nondependent). Prevapor levels of water lever responding were $7.5 \pm 1.3$ (dependent) and $8.4 \pm 1.3$ (nondependent). There was no difference in prevapor responding between the dependent and nondependent groups. The mean BAL across the entire period of ethanol vapor exposure was $180 \pm 36.6 \mathrm{mg} \%$.

Figure 1 shows the effects of D-Phe-CRF ${ }_{12-41}(0.0,0.125,0.25$, and $0.5 \mu \mathrm{g} / \mu \mathrm{l}$ ) administered directly into the CeA on ethanol and water self-administration in dependent and nondependent animals. In the $30 \mathrm{~min}$ test session, after vehicle injection $(0.5 \times$ PBS), the dependent animals pressed $\sim 67$ times $(1.24 \mathrm{~g} / \mathrm{kg})$ for $10 \%$ ethanol compared with 20.2 ethanol presses $(0.36 \mathrm{~g} / \mathrm{kg})$ in the nondependent animals. Based on previous studies from our laboratory, these levels of ethanol intake (grams per kilogram) are estimated to result in BALs ranging from $25-50 \mathrm{mg} \%$ (nondependent) to $125-150 \mathrm{mg} \%$ (dependent) (Roberts et al., 1999). For ethanol self-administration, the two-way ANOVA revealed a significant effect of ethanol exposure $\left(F_{(1,17)}=230.35 ; p<\right.$ $0.0001)$, a significant effect of $\mathrm{D}-\mathrm{Phe}-\mathrm{CRF}_{12-41}$ dose $\left(F_{(3,51)}=\right.$ $20.1 ; p<0.0001)$, and a significant interaction between ethanol exposure and D-Phe-CRF $\mathrm{CR}_{12-41}$ dose $\left(F_{(3,51)}=17.24 ; p<0.0001\right)$. Additional analysis revealed a significant reduction in ethanol self-administration in dependent animals at the $0.5 \mu \mathrm{g} / \mu$ l dose of D-Phe-CRF ${ }_{12-41}$ compared with the $0 \mu \mathrm{g} / \mu \mathrm{l}$ dose $(p<0.0001)$. Furthermore, at the $0.5 \mu \mathrm{g} / \mu \mathrm{l}$ dose of D-Phe-CRF ${ }_{12-41}$, there was no longer a significant difference between the dependent and nondependent groups of animals. However, no dose of D-Phe$\mathrm{CRF}_{12-41}$ was effective in altering ethanol-self administration in nondependent animals $(F<1.0)$. For water self-administration, the two-way ANOVA revealed no effect of ethanol vapor exposure $(F<1.0)$, no effect of D-Phe-CRF ${ }_{12-41}$ dose $(F<1.0)$, and no interaction between ethanol exposure and $\mathrm{D}-\mathrm{Phe}-\mathrm{CRF}_{12-41}$ dose $(F<1.0)$.

A potential caveat is that the site-specific injections may diffuse to other, surrounding brain regions. Thus, degree of spread of the antagonist was determined by an injection of $0.5 \mu \mathrm{l}$ of cresyl violet using the same procedure as outlined above. The dye was localized within each brain site tested. In a few animals, cannula placement was lateral of the CeA (these animals were not included in statistical analyses), and, in these animals, there was little to no reduction in ethanol withdrawal-induced drinking after administration of a CRF antagonist, suggesting that the CeA is an important site for the action of the antagonist. Four animals were removed from this study because of misplaced cannula. Three of these animals were dependent and one nondependent. These animals showed no change in responding (neither depen- 


\section{ETHANOL RESPONSES}

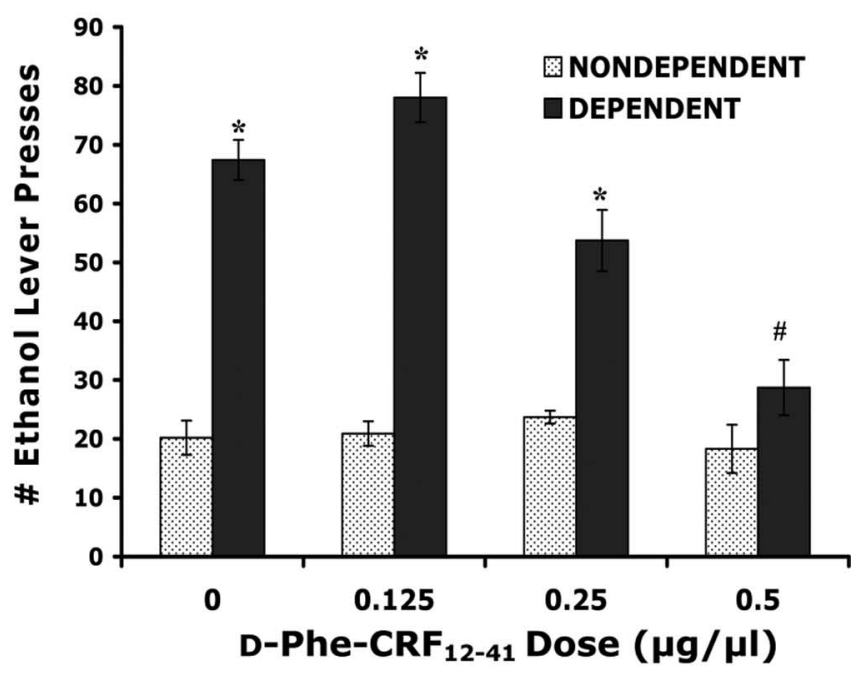

WATER RESPONSES

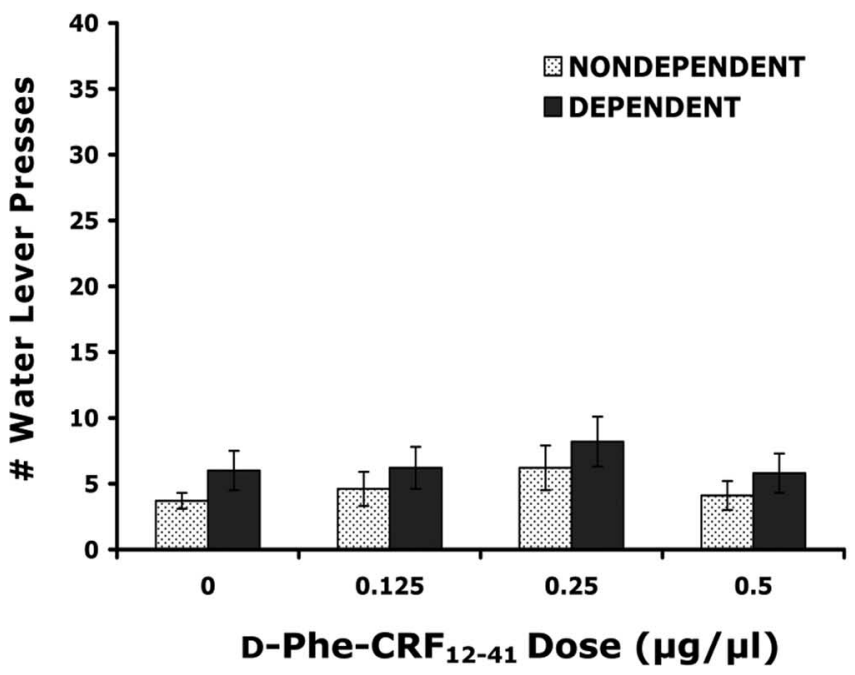

Figure 1. Effects of $D-P h e-C R F_{12-41}$ administered intra-CeA on ethanol and water selfadministration in ethanol-dependent and nondependent rats. Ethanol dependence was induced by intermittent exposure to ethanol vapors for 4 weeks, and animals were subsequently tested for ethanol and water self-administration after $2 \mathrm{~h}$ of acute withdrawal. Withdrawn, ethanol-dependent animals displayed a significant increase in ethanol lever pressing compared with nondependent animals. D-Phe- $\mathrm{CRF}_{12-41}$ significantly decreased ethanol selfadministration in withdrawn, dependent but not nondependent animals when administered directly into the central nucleus of the amygdala. Neither ethanol vapor exposure nor D-Phe$\mathrm{CRF}_{12-41}$ alters water responding. ${ }^{*} p<0.0001$ compared with same drug dose in nondependent animals. ${ }^{*} p<0.0001$ compared with vehicle treatment in dependent animals. Error bars indicate SEM.

dent nor nondependent) in response to D-Phe-CRF ${ }_{12-41}$. The following are the data (average \pm SEM) for ethanol lever responding in the three dependent animals: $0.0 \mu \mathrm{g} / \mu \mathrm{l}$ dose $(72.7 \pm$ 3.9), $0.25 \mu \mathrm{g} / \mu \mathrm{l}(73.6 \pm 3.2), 0.5 \mu \mathrm{g} / \mu \mathrm{l}(70.7 \pm 1.8), 1.0 \mu \mathrm{g} / \mu \mathrm{l}$ $(67.3 \pm 4.1)$.

Effects of the CRF receptor antagonist D-Phe-CRF $\mathrm{F}_{12-41}$ administered intra-lateral BNST on ethanol and water selfadministration in dependent and nondependent rats For the lateral BNST group (dependent, $n=9$; nondependent, $n=8$ ), animal weights at the end of the experiment were $518.1 \pm$

\section{ETHANOL RESPONSES}

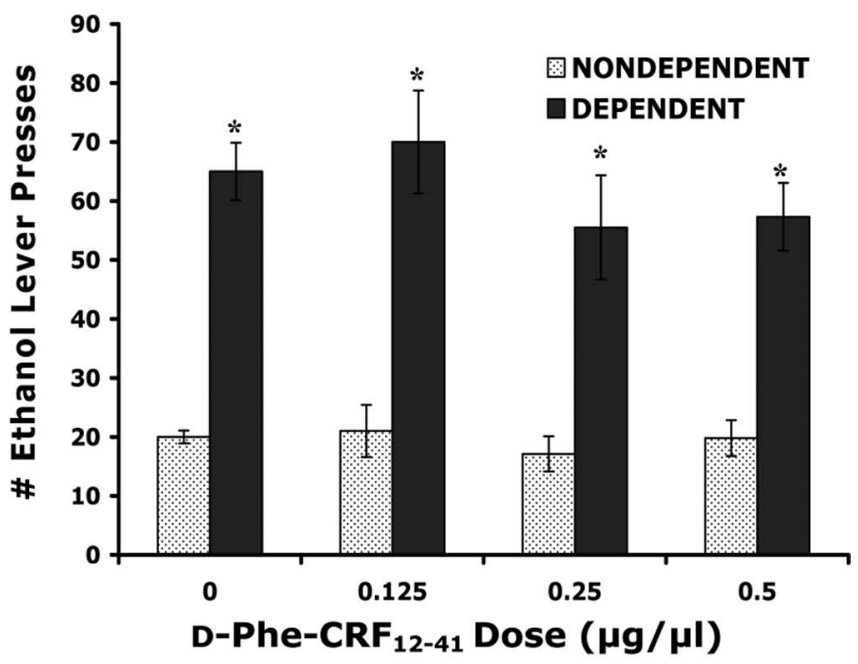

\section{WATER RESPONSES}

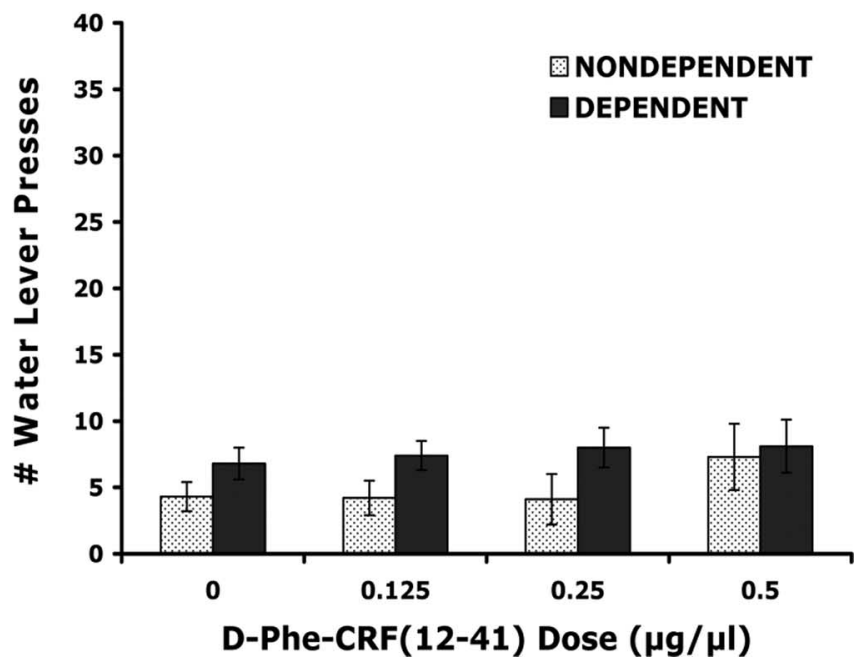

Figure 2. Effects of D-Phe-CRF ${ }_{12-41}$ administered intra-lateral BNST on ethanol and water self-administration in ethanol-dependent and nondependent rats. Ethanol dependence was induced by intermittent exposure to ethanol vapors for 4 weeks, and animals were subsequently tested for ethanol and water self-administration after $2 \mathrm{~h}$ of acute withdrawal. Withdrawn, ethanol-dependent animals displayed a significant increase in ethanol lever pressing compared with nondependent animals. D-Phe- $\mathrm{CRF}_{12-41}$ was without effect in dependent and nondependent animals (on ethanol and water responding) when administered directly into the lateral bed nucleus of the stria terminalis. ${ }^{*} p<0.0001$ compared with same drug dose in nondependent animals. Error bars indicate SEM.

$34.9 \mathrm{~g}$ for nondependent rats and $540.3 \pm 12.5 \mathrm{~g}$ for dependent rats. Levels of ethanol lever responding, before exposure to chronic vapors, were $17.5 \pm 0.9$ presses (dependent) and $15.7 \pm$ 0.9 presses (nondependent). Prevapor levels of water lever responding were $5.6 \pm 1.2$ (dependent) and $6.8 \pm 1.9$ (nondependent). There was no difference in prevapor responding between the dependent and nondependent groups. The mean BAL across the entire period of ethanol vapor exposure was $179.2 \pm 32.7$ $\mathrm{mg} \%$.

Figure 2 shows the effects of D-Phe-CRF ${ }_{12-41}(0.0,0.125,0.25$, and $0.5 \mu \mathrm{g} / \mu \mathrm{l}$ ) administered directly into the lateral BNST on ethanol and water self-administration in dependent and nonde- 
pendent animals. In the $30 \mathrm{~min}$ test session, after vehicle injection (0.5 $\times$ PBS), the dependent animals pressed $\sim 65.2$ times $(1.18$ $\mathrm{g} / \mathrm{kg})$ for $10 \%$ ethanol compared with 19 ethanol presses $(0.28$ $\mathrm{g} / \mathrm{kg}$ ) in nondependent animals. For ethanol self-administration, the two-way ANOVA revealed a significant effect of ethanol exposure $\left(F_{(1,15)}=78.4 ; p<0.0001\right)$ but no effect of D-Phe$\mathrm{CRF}_{12-41}$ dose $\left(F_{(3,45)}=1.11 ; p=.35\right)$ and no interaction between ethanol exposure and D-Phe- $\mathrm{CRF}_{12-41}$ dose $(F<1.0)$. For water self-administration, the two-way ANOVA revealed no effect of ethanol vapor exposure $\left(F_{(1,15)}=4.2 ; p=0.06\right)$, no effect of D-Phe- $\mathrm{CRF}_{12-41}$ dose $(F<1.0)$, and no interaction between ethanol exposure and D-Phe-CRF ${ }_{12-41}$ dose $(F<1.0)$.

Effects of the CRF receptor antagonist D-Phe-CRF $\mathrm{C}_{12-41}$ administered intra-NAcSh on ethanol and water selfadministration in dependent and nondependent rats For the NAcSh group (dependent, $n=7$; nondependent, $n=7$ ), animal weights at the end of the experiment were $602.6 \pm 27.7 \mathrm{~g}$ for nondependent rats and $585.3 \pm 19.2 \mathrm{~g}$ for dependent rats. Levels of ethanol lever responding, before exposure to chronic vapors, were $18.2 \pm 1.3$ presses (dependent) and $17.7 \pm 1.4$ presses (nondependent). Prevapor levels of water lever responding were $5.3 \pm 0.5$ presses (dependent) and $3.4 \pm 0.4$ presses (nondependent). There was no difference in prevapor responding between the dependent and nondependent groups. The mean BAL across the entire period of ethanol vapor exposure was $184.5 \pm 30.8 \mathrm{mg} \%$.

Figure 3 shows the effects of D-Phe-CRF ${ }_{12-41}(0.0,0.125,0.25$, and $0.5 \mu \mathrm{g} / \mu \mathrm{l})$ administered directly into the NAcSh on ethanol and water self-administration in dependent and nondependent animals. In the $30 \mathrm{~min}$ test session, after vehicle injection $(0.5 \times$ PBS), the dependent animals pressed $\sim 61$ times $(1.16 \mathrm{~g} / \mathrm{kg})$ for $10 \%$ ethanol compared with 16 ethanol presses $(0.26 \mathrm{~g} / \mathrm{kg})$ in nondependent animals. For ethanol self-administration, the twoway ANOVA revealed a significant effect of ethanol vapor exposure $\left(F_{(1,12)}=155.4 ; p<0.0001\right)$ but no effect of D-Phe-CRF ${ }_{12-41}$ dose $(F<1.0)$ and no interaction between ethanol exposure and D-Phe-CRF ${ }_{12-41}$ dose $(F<1.0)$. For water self-administration, the two-way ANOVA revealed no effect of ethanol exposure $(F<$ $1.0)$, no effect of D-Phe-CRF ${ }_{12-41}$ dose $(F<1.0)$, and no interaction between ethanol exposure and D-Phe-CRF ${ }_{12-41}$ dose $(F<$ $1.0)$.

\section{Verification of injection site}

Figure 4 illustrates representative light micrographs from each of the brain regions studied, demonstrating site specificity of the cannulas. Probe placements were verified using the Paxinos and Watson (1998) stereotaxic atlas. Only animals with bilateral probe placements in the intended brain regions were used for statistical analysis.

\section{CRF immunoreactivity in the CeA}

Figure 5 shows the relative density of CRF immunoreactivity within the $\mathrm{CeA}(n=3$ animals). Five $40 \mu \mathrm{m}$ serial sections through the CeA for each animal were used for analysis of CRF immunoreactivity. The data were analyzed using Student's $t$ test. From bregma, these sections were $-2.12,-2.30,-2.56,-2.80$, and $-3.14 \mathrm{~mm}$. There was a significant decrease in CRF immunoreactivity in the CeA at bregma -2.80 and $-3.14 \mathrm{~mm}$ in withdrawn, dependent animals relative to control $(p<0.01)$. Total CRF immunoreactivity was also significantly decreased in the CeA (Table 1). Figure 5 also illustrates representative micro-

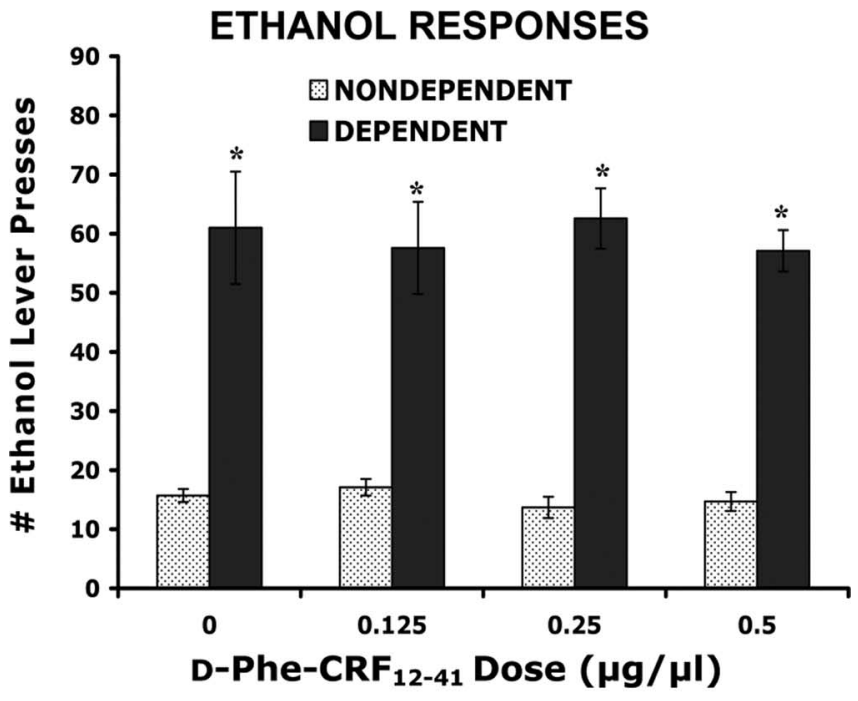

\section{WATER RESPONSES}

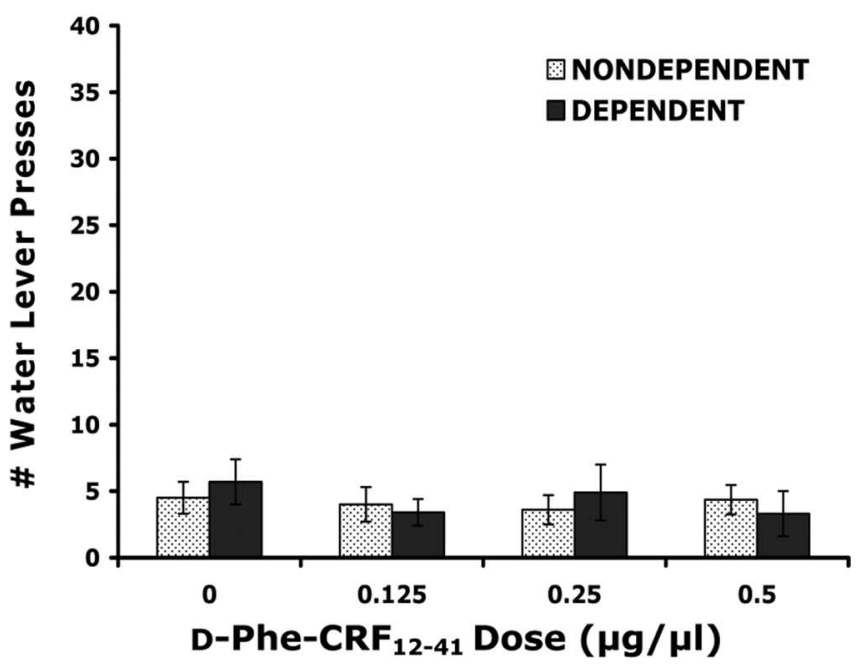

Figure 3. Effects of $D-P h e-C R F_{12-41}$ administered intra-NACSh on ethanol and water selfadministration in ethanol-dependent and nondependent rats. Ethanol dependence was induced by intermittent exposure to ethanol vapors for 4 weeks, and animals were subsequently tested for ethanol and water self-administration after $2 \mathrm{~h}$ of acute withdrawal. Withdrawn, ethanol-dependent animals displayed a significant increase in ethanol lever pressing compared with nondependent animals. D-Phe- $\mathrm{CRF}_{12-41}$ was without effect in dependent and nondependent animals (on ethanol and water responding) when administered directly into the shell of the nucleus accumbens. ${ }^{*} p<0.0001$ compared with same drug dose in nondependent animals. Error bars indicate SEM.

graphs from the CeA (bregma $-2.80 \mathrm{~mm}$ ), demonstrating CRF staining within this brain region.

In addition to quantifying total CRF immunoreactivity within the CeA, the total number of CRF-positive cells was also analyzed. The total number of CRF-positive cells (estimated total optical fractionator) was $1580 \pm 125.3$ for nondependent animals and $1295 \pm 80$ for dependent animals. There was no significant difference between the two groups of animals ( $p=0.188$ ). Thus, the significant decrease in total CRF immunoreactivity within the CeA likely reflects a decrease in CRF within fibers. 


\section{Central Nucleus of the Amygdala}

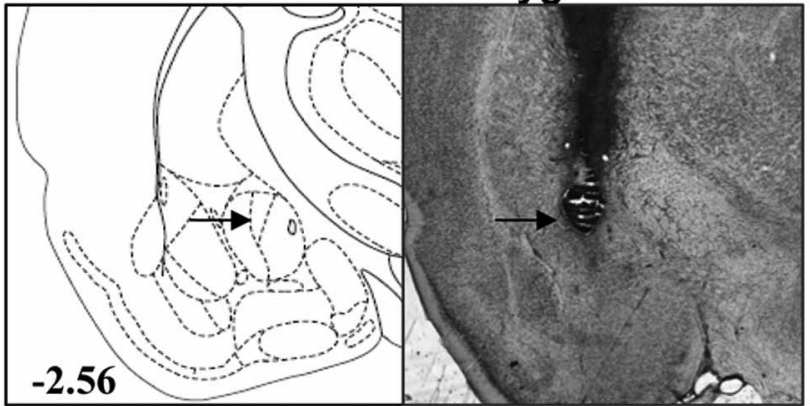

\section{Bed Nucleus of The Stria Terminalis, lateral}

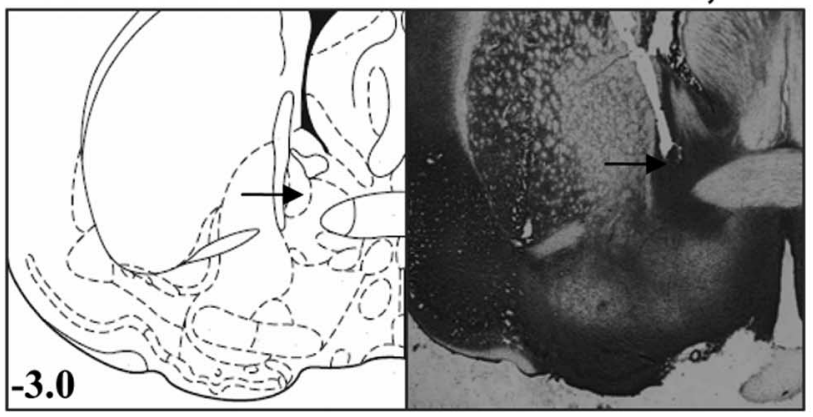

\section{Nucleus Accumbens Shell}

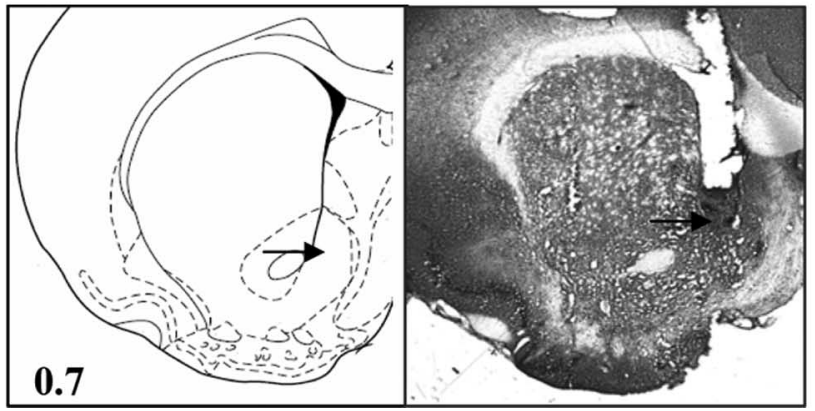

Figure 4. Representative cannula site verification micrographs. At the completion of the experiments, brains were sectioned at $60 \mu \mathrm{m}$ intervals, mounted, and stained with cresy violet. Injection sites were verified under a light microscope. Only animals with correct, bilateral cannula placement were used for statistical analysis. Figures display representative slides from the CeA, lateral BNST, and NACSh. Numbers in diagrams represent distance from bregma, based on the rat brain atlas by Paxinos and Watson (1998).

\section{CRF immunoreactivity in the lateral BNST}

Figure 6 shows the relative density of CRF immunoreactivity within the lateral BNST ( $n=3$ animals). Five $40 \mu \mathrm{m}$ serial sections through the lateral BNST for each animal were used for analysis of CRF immunoreactivity. The data were analyzed using Student's $t$ test. From bregma, these regions were $-0.20,-0.26$, $-0.30,-0.40$, and $-0.80 \mathrm{~mm}$. Although there was a trend toward a decrease in dependent animals, there was no significant change in CRF immunoreactivity in the BNST in dependent animals compared with control. Total CRF immunoreactivity was also not significantly altered in the lateral BNST $(p=0.08)(\mathrm{Ta}-$ ble 1). Figure 6 also illustrates representative micrographs from the lateral BNST (bregma $-0.3 \mathrm{~mm}$ ), demonstrating CRF staining within this brain region.

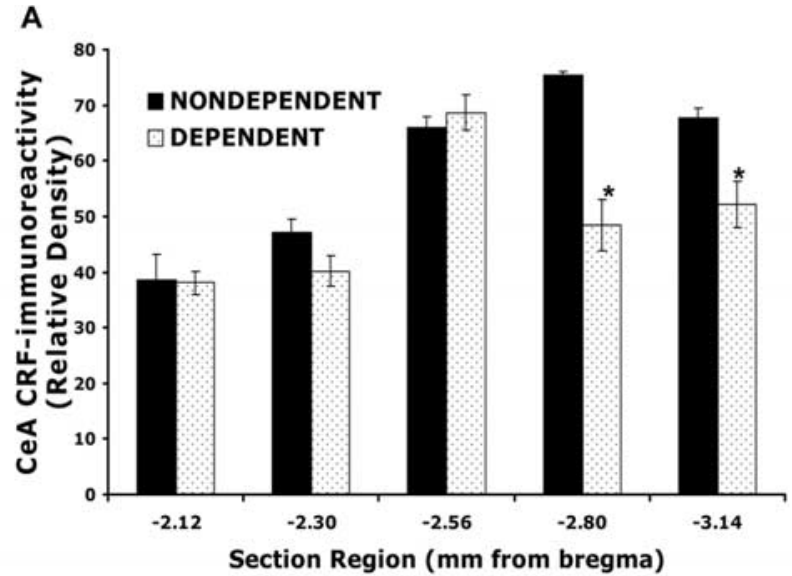

B
Nondependent

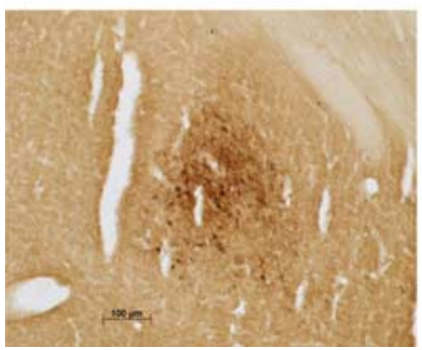

Dependent

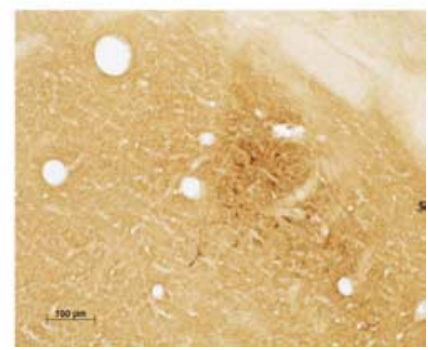

Figure 5. CRF immunoreactivity in the CeA. Ethanol dependence was induced by intermittent exposure to ethanol vapors for 4 weeks, and animals were killed after $2 \mathrm{~h}$ of withdrawal. Brains were removed and CRF expression was measured in the central nucleus of the amygdala using immunohistochemical techniques. The data are expressed as the relative density of CRF immunoreactivity ( $n=3$ animals). $A$, CRF immunoreactivity was measured from five serial sections throughout the CeA. From bregma, these sections were $-2.12,-2.30,-2.56$, -2.80 , and $-3.14 \mathrm{~mm}$. There was a significant decrease in CRF immunoreactivity in the CeA at bregma -2.80 and $-3.14 \mathrm{~mm}$ in withdrawn, dependent animals relative to control. $\boldsymbol{B}$, Representative micrographs $(20 \times)$ from the $C e A($ bregma $-2.80 \mathrm{~mm}$ ) demonstrating CRF staining within this brain region. ${ }^{*} p<0.01$ compared with nondependent animals. Error bars indicate SEM.

Table 1. Total CRF immunoreactivity in the CeA and lateral BNST

\begin{tabular}{lll}
\hline & Total density, CeA & Total density, lateral BNST \\
\hline Nondependent & $294.9 \pm 9.4$ & $251.5 \pm 10.1$ \\
Ethanol dependent & $247.6 \pm 7.1^{*}$ & $230.7 \pm 4.6$
\end{tabular}

Ethanol dependence was induced by intermittent exposure to ethanol vapors for 4 weeks, and animals were killed after $2 \mathrm{~h}$ of withdrawal. Brains were removed, and CRF expression was measured in the CeA and lateral BNST using immunohistochemical techniques. The data are expressed as the relative density of CRF immunoreactivity ( $n=3$ animals) and represent the total (RF immunoreactivity within all five bregma sections of each brain area. There was a significant decrease of total CRF immunoreactivity in the CeA of ethanol-dependent animals relative to control. ${ }^{*} p<0.01$ compared with nondependent animals.

CRF immunoreactivity in the NAcSh

We observed no detectable CRF immunoreactivity within the NAcSh of ethanol-dependent or nondependent animals (data not shown).

\section{Discussion}

Excessive, uncontrolled drinking and the presence of a withdrawal syndrome after cessation of alcohol intake are two of the diagnostic criteria for dependence in humans (American Psychiatric Association, 1994). Furthermore, human alcoholics report that a negative emotional state, especially enhanced anxiety, experienced during withdrawal is an important factor eliciting relapse and binge drinking during periods of abstinence (Hershon, 
A

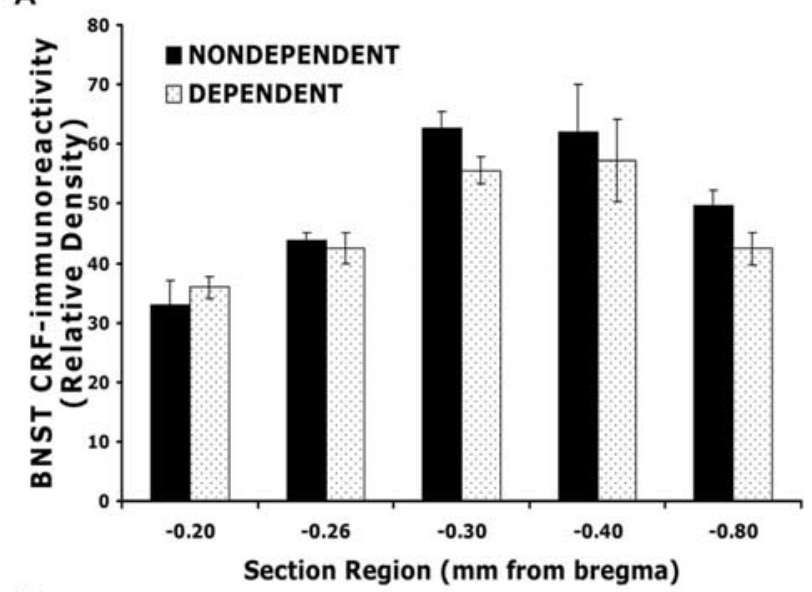

B

Nondependent
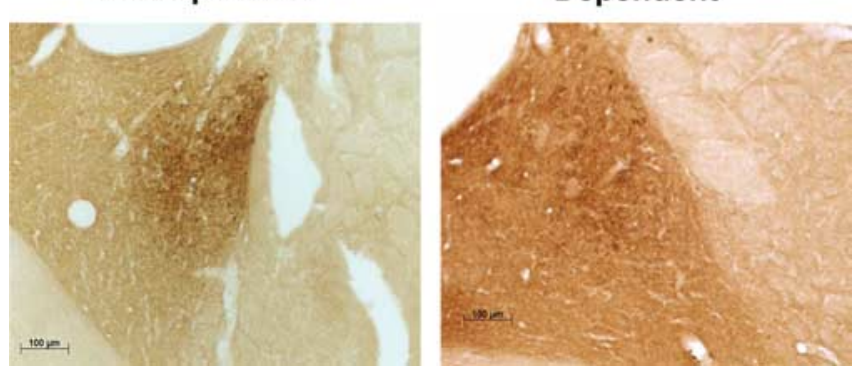

Figure 6. CRF immunoreactivity in the lateral BNST. Ethanol dependence was induced by intermittent exposure to ethanol vapors for 4 weeks, and animals were killed after $2 \mathrm{~h}$ of withdrawal. Brains were removed and CRF expression was measured in the lateral BNST using immunohistochemical techniques. The data are expressed as the relative density of CRF immunoreactivity ( $n=3$ animals). $\boldsymbol{A}$, CRF immunoreactivity was measured from five serial sections throughout the lateral BNST. From bregma, these sections were $-0.20,-0.26,-0.30$, -0.40 , and $-0.80 \mathrm{~mm}$. Although there was a trend toward a decrease in dependent animals, there was no significant change in CRF immunoreactivity in the BNST in dependent animals compared with control. $\boldsymbol{B}$, Representative micrographs $(20 \times)$ from the lateral BNST (bregma $-0.30 \mathrm{~mm}$ ) demonstrating (RF staining within this brain region. Error bars indicate SEM.

1977). Animal model systems for ethanol dependence have been developed that mimic excessive drinking and withdrawal (Roberts et al., 2000; Rimondini et al., 2002; O'Dell et al., 2004). It has been hypothesized that withdrawal-induced behaviors may result from "kindling"-like processes (Becker, 1998; Breese et al., 2005). Repeated withdrawals from a chronic ethanol diet increase anxiety-like behaviors, whereas this effect is not seen in rats exposed continuously to alcohol (Overstreet et al., 2002). Furthermore, intermittent ethanol vapor exposure induces a more rapid increase in self-administration of ethanol relative to continuous exposure (O'Dell et al., 2004). Here, animals were made dependent by chronic exposure to intermittent ethanol vapors and tested after a $2 \mathrm{~h}$ period of withdrawal, a time point in which dependent animals display both heightened anxiety-like behaviors and increased ethanol self-administration (Valdez et al., 2002). The data reported here show that a CRF antagonist, administered into the $\mathrm{CeA}$, significantly reduces ethanol selfadministration in ethanol-dependent rats but not in nondependent rats. Similar injections localized to the BNST and nucleus accumbens shell had no effect. These results provide key information about the functional organization of CRF systems in mediating critical motivational aspects of alcohol dependence.

A dysregulation of brain CRF "stress" systems appears to mediate, in part, the negative reinforcement associated with ethanol withdrawal. Both the hypothalamic CRF stress system, which plays a role in mediating the neuroendocrine responses to stress (Vale et al., 1981; Rivier et al., 1982), and the extrahypothalamic CRF system, which mediates the behavioral and autonomic responses to stress and anxiety (LeDoux et al., 1988; Walker and Davis, 1997), become dysregulated as ethanol dependence progresses. In rats, acute ethanol activates the hypothalamicpituitary-adrenal (HPA) axis (Rivier et al., 1984), whereas chronic ethanol, as well as ethanol withdrawal, attenuates HPA axis activity (Rivier et al., 1990; Zorrilla et al., 2001). In contrast, extrahypothalamic CRF systems become hyperactive during withdrawal (Merlo Pich et al., 1995; Olive et al., 2002). Here, after a 4 week period of ethanol vapor exposure to induce ethanol dependence, a decrease in total CRF immunoreactivity within the $\mathrm{CeA}$ is reported. These data correlate with previous studies showing a decrease in CRF-like immunoreactivity within the amygdala of rats withdrawn from a chronic ethanol liquid diet (Zorrilla et al., 2001). The decreased expression of CRF within the CeA in dependent animals is hypothesized to result from increased exocytosis of CRF from nerve terminals (Merlo Pich et al., 1995). In accordance with this hypothesis, the total number of CRFpositive cells was not significantly altered in the CeA of dependent animals relative to nondependent controls, indicating that the significant decrease in total CRF immunoreactivity likely reflects a decrease in CRF within fibers (because of increased exocytosis).

CRF within the CeA mediates anxiety-like behaviors in animals (Heinrichs et al., 1992; Liang et al., 1992; Walker and Davis, 1997), and the CeA receives multiple sources of input from CRFrich areas, including the basolateral nucleus, the lateral BNST, and paraventricular hypothalamic nucleus (Uryu et al., 1992; Sun and Cassell, 1993; Cassell et al., 1999). During withdrawal, there is an increase in extracellular CRF within the CeA of dependent rats (Merlo Pich et al., 1995), and the data presented here suggest that CRF within the CeA plays an important role in mediating enhanced ethanol self-administration during acute withdrawal. Because the increase in extracellular CRF was observed to begin $6 \mathrm{~h}$ after withdrawal and the behavioral effects of CRF antagonists at $2 \mathrm{~h}$, the argument may be made that $\mathrm{D}-\mathrm{Phe}-\mathrm{CRF}_{12-41}$ is acting indirectly to decrease ethanol self-administration. However, these timing differences can likely be explained by procedural differences. Merlo Pich et al. (1995) used an ethanol liquid diet for 2 weeks, which yielded an average BAL of $\sim 125 \mathrm{mg} \%$. Using the ethanol vapor method, a much higher and more stable average BAL was attained (175-200 mg\%) for 4 weeks. Furthermore, intermittent versus chronic ethanol exposure can induce dependence much more rapidly (O'Dell et al., 2004), thus the precipitous drop in blood alcohol levels would be a powerful withdrawal response at $2 \mathrm{~h}$ into withdrawal. Administration of CRF antagonists directly into the CeA of ethanol-dependent animals has been shown to reduce anxiety-like behaviors after acute withdrawal (Rassnick et al., 1993), supporting the hypothesis that animals consume excessive amounts of ethanol during withdrawal to alleviate "anxiety" produced by withdrawal. Furthermore, lesions of the CeA reduce the anxiogenic-like effect of restraint stress and reduce voluntary ethanol intake (Moller et al., 1997), demonstrating the importance of this brain region in mediating anxiety and ethanol consumption.

The cellular mechanisms underlying the enhancement of ethanol self-administration by enhanced CRF activity remain unknown. Studies suggest a role for GABA neurotransmitter systems and, at the molecular level, protein kinase signaling pathways. In ethanol-dependent rats, there is an increased 
GABAergic transmission within the CeA (Roberto et al., 2004), an effect likely mediated by CRF systems (Nie et al., 2004). It is suggested that $\mathrm{CRF}_{1}$ receptors, within the CeA, may act as autoreceptors and chronic ethanol exposure may increase this CRFmediated autoinhibition. Furthermore, the increase in GABAergic activity within the CeA may lead to excitation by disinhibiting downstream neurons (Nie et al., 2004). Protein kinase signaling pathways may also be involved in CRF-mediated increases in ethanol withdrawal-induced behaviors (Pandey et al., 2003). There are two types of high-affinity CRF receptors, $\mathrm{CRF}_{1}$ (Chang et al., 1993; Chen et al., 1993) and $\mathrm{CRF}_{2}$ (Lovenberg et al., 1995), both inducing an increase in intracellular cAMP and protein kinase A (PKA) activation during stimulation (Giguere et al., 1982; Chen et al., 1986). During acute withdrawal in rats, there is a reduction in the phosphorylation of cAMP-response element binding protein in the $\mathrm{CeA}$, correlating with increased anxietylike behaviors and ethanol drinking (Pandey et al., 2003). These data suggest that the activity of the cAMP/PKA signaling pathway is also decreased during withdrawal, which may result from altered CRF receptor expression and/or altered CRF receptor coupling within the CeA.

Within the NAcSh, the CRF antagonist was without effect, consistent with the known role of this brain region in mediating primarily the positive reinforcing properties of ethanol (Di Chiara and Imperato, 1988; Koob and Le Moal, 1997). D-Phe-CRF ${ }_{12-}$ 41, administered into the lateral BNST, also was without effect. Furthermore, there was no significant change in CRF immunoreactivity within the lateral BNST. These results are somewhat surprising because extracellular CRF release is also elevated within the BNST during withdrawal (Olive et al., 2002), and, like the CeA, the BNST plays a role in mediating anxiety-like behaviors (Walker and Davis, 1997). However, studies suggest that, although the CeA and lateral BNST mediate similar behaviors, they are activated in response to different types of stressors (Walker and Davis, 1997). For example, administration of a CRF antagonist into the CeA attenuates morphine priming-induced reinstatement of morphine conditioned place preference (CPP), whereas administration of the antagonist into the BNST attenuates footshock-stress-induced reinstatement of morphine CPP (Wang et al., 2006). Furthermore, administration of a CRF antagonist in the lateral BNST, but not CeA, reduces stress-induced cocaine reinstatement (Erb and Stewart, 1999), and administration of a CRF antagonist into the CeA, but not lateral BNST, reduces the behavioral signs of opiate withdrawal in opiatedependent animals (Heinrichs et al., 1995; McNally and Akil, 2002). Although the mechanisms by which each region preferentially contributes to ethanol withdrawal-induced anxiety-like behavior remain unknown, our data suggest that the CeA plays a primary role in the expression of excessive ethanol selfadministration in dependent animals.

D-Phe- $\mathrm{CRF}_{12-41}$ binds to and inhibits both $\mathrm{CRF}_{1}$ and $\mathrm{CRF}_{2}$ receptors. The $\mathrm{CRF}_{1}$ receptor plays an important role in mediating anxiety-like behavior (Heinrichs et al., 1997; Smith et al., 1998; Timpl et al., 1998; Muller et al., 2003; Zorrilla and Koob, 2004). These data, along with studies demonstrating the importance of $\mathrm{CRF}_{1}$ in mediating alcohol withdrawal inducedbehaviors (Overstreet et al., 2004) and ethanol selfadministration (Funk et al., 2006), suggest the potential of developing novel $\mathrm{CRF}_{1}$ compounds for the treatment of alcohol dependence. However, because chronic exposure to some $\mathrm{CRF}_{1}$ antagonists have been shown to alter dopaminergic systems (Lawrence et al., 2005) and cholecystokinin systems (Lodge and Lawrence, 2003), it will be important to more thoroughly inves- tigate the chronic effects of these antagonists. A few studies also suggest a potential role for $\mathrm{CRF}_{2}$ receptors in mediating ethanol withdrawal-induced behaviors, albeit in an opposite manner to $\mathrm{CRF}_{1}$ (Valdez et al., 2003).

In summary, the present study shows a site-specific action of CRF in mediating excessive ethanol intake during withdrawal in dependent rats. These data have important clinical implications for the treatment of alcohol dependence in humans. Dysregulation of CRF stress systems may represent a long-lasting change within the brain resulting from chronic ethanol consumption, and the present study pinpoints the CeA as a critical region for these changes. During cessation of ethanol use, CRF stress systems become overactive, likely causing negative emotional states in humans, such as heightened anxiety. Novel pharmacotherapies aimed at treating alcohol-induced anxiety and depression may prove to be successful in treating relapse and excessive drinking during withdrawal.

\section{References}

American Psychiatric Association (1994) Diagnostic and statistical manual of mental disorders, Ed 4. Washington, DC: American Psychiatric Press.

Baldwin HA, Rassnick S, Rivier J, Koob GF, Britton KT (1991) CRF antagonist reverses the "anxiogenic" response to ethanol withdrawal in the rat. Psychopharmacology (Berl) 103:227-232.

Becker HC (1998) Kindling in alcohol withdrawal. Alcohol Health Res World 22:25-33.

Becker HC (1999) Alcohol withdrawal: neuroadaptation and sensitization. CNS Spectrums 4:38-65.

Becker HC, Lopez MF (2004) Increased ethanol drinking after repeated chronic ethanol exposure and withdrawal experience in C57BL/6 mice. Alcohol Clin Exp Res 28:1829-1838.

Breese GR, Overstreet DH, Knapp DJ (2005) Conceptual framework for the etiology of alcoholism: a "kindling"/stress hypothesis. Psychopharmacology (Berl) 178:367-380.

Cassell MD, Freedman LJ, Shi C (1999) The intrinsic organization of the central extended amygdala. Ann NY Acad Sci 877:217-241.

Chang CP, Pearse II RV, O’Connell S, Rosenfeld MG (1993) Identification of a seven transmembrane helix receptor for corticotropin-releasing factor and sauvagine in mammalian brain. Neuron 11:1187-1195.

Chen FM, Bilezikjian LM, Perrin MH, Rivier J, Vale W (1986) Corticotropin releasing factor receptor-mediated stimulation of adenylate cyclase activity in the rat brain. Brain Res 381:49-57.

Chen R, Lewis KA, Perrin MH, Vale WW (1993) Expression cloning of a human corticotropin-releasing factor receptor. Proc Natl Acad Sci USA 90:8967-8971.

Di Chiara G, Imperato A (1988) Drugs abused by humans preferentially increase synaptic dopamine concentrations in the mesolimbic system of freely moving rats. Proc Natl Acad Sci USA 85:5274-5278.

Dong HW, Petrovich GD, Swanson LW (2001) Topography of projections from amygdala to bed nuclei of the stria terminalis. Brain Res Brain Res Rev 38:192-246.

Erb S, Stewart J (1999) A role for the bed nucleus of the stria terminalis, but not the amygdala, in the effects of corticotropin-releasing factor on stressinduced reinstatement of cocaine seeking. J Neurosci 19:RC35(1-6).

Funk CK, Zorrilla EP, Lee MJ, Rice KC, Koob GF (2006) CRF1 antagonists selectively reduce ethanol self-administration in ethanol-dependent rats. Biol Psychiatry, in press.

Giguere V, Labrie F, Cote J, Coy DH, Sueiras-Diaz J, Schally AV (1982) Stimulation of cyclic AMP accumulation and corticotropin release by synthetic ovine corticotropin-releasing factor in rat anterior pituitary cells: site of glucocorticoid action. Proc Natl Acad Sci USA 79:3466-3469.

Heinrichs SC, Pich EM, Miczek KA, Britton KT, Koob GF (1992) Corticotropin-releasing factor antagonist reduces emotionality in socially defeated rats via direct neurotropic action. Brain Res 581:190-197.

Heinrichs SC, Menzaghi F, Schulteis G, Koob GF, Stinus L (1995) Suppression of corticotropin-releasing factor in the amygdala attenuates aversive consequences of morphine withdrawal. Behav Pharmacol 6:74-80.

Heinrichs SC, Lapsansky J, Lovenberg TW, De Souza EB, Chalmers DT (1997) Corticotropin-releasing factor CRF1, but not CRF2, receptors mediate anxiogenic-like behavior. Regul Pept 71:15-21. 
Hershon HI (1977) Alcohol withdrawal symptoms and drinking behavior. J Stud Alcohol 38:953-971.

Koob GF (2003) Neuroadaptive mechanisms of addiction: studies on the extended amygdala. Eur Neuropsychopharmacol 13:442-452.

Koob GF, Le Moal M (1997) Drug abuse: hedonic homeostatic dysregulation. Science 278:52-58.

Koob GF, Ahmed SH, Boutrel B, Chen SA, Kenny PJ, Markou A, O'Dell LE, Parsons LH, Sanna PP (2004) Neurobiological mechanisms in the transition from drug use to drug dependence. Neurosci Biobehav Rev 27:739-749.

Lawrence AJ, Parish CL, Chen F, Lodge DJ, Krstew EV, Card K, Finkelstein DI, Horne MK (2005) Chronic corticotropin-releasing factor type 1 receptor antagonism with antalarmin regulates the dopaminergic system of Fawn-Hooded rats. J Neurochem 94:1523-1534.

LeDoux JE, Iwata J, Cicchetti P, Reis DJ (1988) Different projections of the central amygdaloid nucleus mediate autonomic and behavioral correlates of conditioned fear. J Neurosci 8:2517-2529.

Liang KC, Melia KR, Campeau S, Falls WA, Miserendino MJD, Davis M (1992) Lesions of the central nucleus of the amygdala, but not the paraventricular nucleus of the hypothalamus, block the excitatory effects of corticotropin-releasing factor on the acoustic startle reflex. J Neurosci 12:2313-2320.

Lodge DJ, Lawrence AJ (2003) The effect of chronic CRF1 receptor blockade on the central CCK systems of Fawn-Hooded rats. Regul Pept 116:27-33.

Lovenberg TW, Liaw CW, Grigoriadis DE, Clevenger W, Chalmers DT, De Souza EB, Oltersdorf T (1995) Cloning and characterization of a functionally distinct corticotropin-releasing factor receptor subtype from rat brain. Proc Natl Acad Sci USA 92:836-840.

McNally GP, Akil H (2002) Role of corticotropin-releasing hormone in the amygdala and bed nucleus of the stria terminalis in the behavioral, pain modulatory, and endocrine consequences of opiate withdrawal. Neuroscience 112:605-617.

Menzaghi F, Rassnick S, Heinrichs S, Baldwin H, Pich EM, Weiss F, Koob GF (1994) The role of corticotropin-releasing factor in the anxiogenic effects of ethanol withdrawal. Ann NY Acad Sci 739:176-184.

Merchenthaler I, Vigh S, Petrusz P, Schally AV (1982) Immunocytochemical localization of corticotropin-releasing factor (CRF) in the rat brain. Am J Anat 165:385-396.

Merlo Pich E, Lorang M, Yeganeh M, Rodriquez de Fonseca F, Raber J, Koob GF, Weiss F (1995) Increase of extracellular corticotropin-releasing factor-like immunoreactivity levels in the amygdala of awake rats during restraint stress and ethanol withdrawal as measured by microdialysis. J Neurosci 15:5439-5447.

Moller C, Wiklund L, Sommer W, Thorsell A, Heilig M (1997) Decreased experimental anxiety and voluntary ethanol consumption in rats following central but not basolateral amygdala lesions. Brain Res 760:94-101.

Muller MB, Zimmerman S, Sillaber I, Hagemeyer TP, Deussing JM, Timpl P, Kormann MS, Droste SK, Kuhn R, Reul JM, Holsboer F, Wurst W (2003) Limbic corticotropin-releasing hormone receptor 1 mediates anxietyrelated behavior and hormonal adaptation to stress. Nat Neurosci 6:1100-1107.

Nie Z, Schweitzer P, Roberts AJ, Madamba SG, Moore SD, Siggins GR (2004) Ethanol augments GABAergic transmission in the central amygdala via CRF1 receptors. Science 303:1512-1514.

O’Dell LE, Roberts AJ, Smith RT, Koob GF (2004) Enhanced alcohol selfadministration after intermittent versus continuous alcohol vapor exposure. Alcohol Clin Exp Res 28:1676-1682.

Olive MF, Koenig HN, Nannini MA, Hodge CW (2002) Elevated extracellular CRF levels in the bed nucleus of the stria terminalis during ethanol withdrawal and reduction by subsequent ethanol intake. Pharmacol Biochem Behav 72:213-220.

Overstreet DH, Knapp DJ, Breese GR (2002) Accentuated decrease in social interaction in rats subjected to repeated ethanol withdrawals. Alcohol Clin Exp Res 26:1259-1268.

Overstreet DH, Knapp DJ, Breese GR (2004) Modulation of multiple ethanol withdrawal-induced anxiety-like behavior by CRF and CRF1 receptors. Pharmacol Biochem Behav 77:405-413.

Pandey SC, Roy A, Zhang H (2003) The decreased phosphorylation of cyclic adenosine monophosphate (cAMP) response element binding (CREB) protein in the central amygdala acts as a molecular substrate for anxiety related to ethanol withdrawal in rats. Alcohol Clin Exp Res 27:396-409.
Paxinos G, Watson C (1998) The rat brain in stereotaxic coordinates. New York: Academic.

Rassnick S, Heinrichs SC, Britton KT, Koob GF (1993) Microinjection of a corticotropin-releasing factor antagonist into the central nucleus of the amygdala reverses anxiogenic-like effects of ethanol withdrawal. Brain Res 605:25-32.

Rimondini R, Arlinde C, Sommer W, Heilig M (2002) Long-lasting increase in voluntary ethanol consumption and transcriptional regulation in the rat brain after intermittent exposure to alcohol. FASEB J 16:27-35.

Rivier C, Rivier J, Vale W (1982) Inhibition of adrenocorticotropic hormone secretion in the rat by immunoneutralization of corticotropinreleasing factor. Science 218:377-379.

Rivier C, Bruhn T, Vale W (1984) Effect of ethanol on the hypothalamicpituitary-adrenal axis in the rat: role of corticotropin-releasing factor (CRF). J Pharmacol Exp Ther 229:127-131.

Rivier C, Imaki T, Vale W (1990) Prolonged exposure to alcohol: effect on CRF mRNA levels, and CRF and stress-induced ACTH secretion in the rat. Brain Res 520:1-5.

Roberto M, Madamba SG, Stouffer DG, Parsons LH, Siggins GR (2004) Increased GABA release in the central amygdala of ethanol-dependent rats. J Neurosci 24:10159-10166.

Roberts AJ, Heyser CJ, Koob GF (1999) Operant self-administration of sweetened versus unsweetened ethanol: effects on blood alcohol levels. Alcohol Clin Exp Res 23:1151-1157.

Roberts AJ, Heyser CJ, Cole M, Griffin P, Koob GF (2000) Excessive ethanol drinking following a history of dependence: animal model of allostasis. Neuropsychopharmacology 22:581-594.

Samson HH (1986) Initiation of ethanol reinforcement using a sucrosesubstitution procedure in food- and water-sated rats. Alcohol Clin Exp Res 10:436-442.

Smith GW, Aubry JM, Dellu F, Contarino A, Bilezikjiam LM, Gold LH, Chen R, Marchuk Y, Hauser C, Bentley CA, Sawchenko PE, Koob GF, Vale W, Lee KF (1998) Corticotropin-releasing factor receptor 1-deficient mice display decreased anxiety, impaired stress response, and aberrant neuroendocrine development. Neuron 20:1093-1102.

Sun N, Cassell MD (1993) Intrinsic GABAergic neurons in the rat central extended amygdala. J Comp Neurol 330:381-404.

Timpl P, Spanagel R, Sillaber I, Kresse A, Reul JMHM, Stalla GK, Blanquet V, Steckler T, Holsboer F, Wurst W (1998) Impaired stress response and reduced anxiety in mice lacking a functional corticotropin-releasing hormone receptor 1. Nat Genet 19:162-166.

Uryu K, Okumura T, Shibasaki T, Sakanaka M (1992) Fine structure and possible origins of nerve fibers with corticotropin-releasing factor-like immunoreactivity in the rat central amygdaloid nucleus. Brain Res 577:175-179.

Valdez GR, Roberts AJ, Chan K, Davis H, Brennan M, Zorrilla EP, Koob GF (2002) Increased ethanol self-administration and anxiety-like behavior during acute ethanol withdrawal and protracted abstinence: regulation by corticotropin-releasing factor. Alcohol Clin Exp Res 26:1494-1501.

Valdez GR, Zorrilla EP, Rivier J, Vale WW, Koob GF (2003) Locomotor suppressive and anxiolytic-like effects of urocortin 3, a highly selective type 2 corticotropin-releasing factor agonist. Brain Res 980:206-212.

Vale W, Spiess J, Rivier C, Rivier J (1981) Characterization of a 41-residue ovine hypothalamic peptide that stimulates secretion of corticotropin and beta-endorphin. Science 213:1394-1397.

Van Pett K, Viau V, Bittencourt JC, Chan RKW, Li HY, Arias C, Prins GS, Perrin M, Vale W, Sawchenko PE (2000) Distribution of mRNAs encoding CRF receptors in brain and pituitary of rat and mouse. J Comp Neurol 428:191-212.

Walker DL, Davis M (1997) Double dissociation between the involvement of the bed nucleus of the stria terminalis and the central nucleus of the amygdala in startle increases produced by conditioned versus unconditioned fear. J Neurosci 17:9375-9383.

Wang J, Fang Q, Liu Z, Lu L (2006) Region-specific effects of brain corticotropin-releasing factor receptor type 1 blockade on footshockstress- or drug-priming-induced reinstatement of morphine conditioned place preference in rats. Psychopharmacology (Berl) 185:19-28.

Zorrilla EP, Koob GF (2004) The therapeutic potential of CRF1 antagonists for anxiety. Expert Opin Investig Drugs 13:799-828.

Zorrilla EP, Valdez GR, Weiss F (2001) Changes in levels of regional CRFlike immunoreactivity and plasma corticosterone during protracted drug withdrawal in dependent rats. Psychopharmacology 158:374-381. 